\title{
A fuzzy AHP approach for employee recruitment
}

\author{
Mohsen Varmazyar* and Behrouz Nouri
}

Department of Strategic Planning, Research Institute of Petroleum Industry (RIPI), Iran

\begin{tabular}{|c|c|}
\hline$\overline{C H R O N I C L E}$ & A B S T R A C T \\
\hline $\begin{array}{l}\text { Article history: } \\
\text { Received January } 15,2013 \\
\text { Accepted August } 12,2013 \\
\text { Available online } \\
\text { August } 272013 \\
\text { Keywords: } \\
\text { Fuzzy Analytic Hierarchy Process } \\
\text { MCDM } \\
\text { AHP }\end{array}$ & $\begin{array}{l}\text { Human resource management plays an essential role on development of any business } \\
\text { organization. Selection of employee normally depends on various criteria such as employee } \\
\text { commitment, necessary skills, etc. Therefore, a good strategy to hire appropriate employee is a } \\
\text { multi-criteria decision making (MCDM) specially the ones, which could handle uncertainty, } \\
\text { properly. In this paper, we present a method to use MCDM techniques for hiring employees. In } \\
\text { fact, the present work proposes a Fuzzy Analytic Hierarchy Process (FAHP) as one of the most } \\
\text { popular multi-criteria decision making techniques. A computer application is developed where } \\
\text { it receives the configuration of the employee selection problem, evaluates the candidates and } \\
\text { ranks them using the appropriate voting system. }\end{array}$ \\
\hline
\end{tabular}

(C) 2014 Growing Science Ltd. All rights reserved.

\section{Introduction}

These days, many contemporary organizations are confronted with lofty levels of competition in the international market. The future survival of most firms contingent on the commitment of their employee to companies because of increasingly competitive world market. In addition, employee skills such as capability, knowledge, skill, and other capabilities play a foremost function for the success of any organization.

Human Resource Management (HRM) is a process of managing people through employee selection, performance evaluation, reward systems, training and development. A common principle among business academics and practitioners is that HRM should be based on justice principles, particularly in hiring, performance evaluation and rewarding. The justice principles are understood as the process of decision making to be carried out with the minimal impact on subjective judgments.

* Corresponding author.

E-mail addresses: varmazyarm@ripi.ir (M. Varmazyar)

(C) 2013 Growing Science Ltd. All rights reserved.

doi: $10.5267 /$ j.dsl.2013.08.006 
The recruitment procedure is the first step to plan for a future employee with an organization. Recent research has confirmed that the employee's commitment to the organization depends on the employee's treatment for the recruitment process (Bowen et al., 1999). If the employees are treated properly during the selection period, they will be more likely committed to the organization.

Literature review illustrates that the challenging task of trying to decide on good quality workers from weak ones start with the implementation of psychology tests (Blum \& Naylor, 1968). The principles of employee selection have changed very little since Freyd (1923) published his guidelines. Blunt mentions that in practice, personnel recruitment is carried out less rigorously than it should be in many cases (Blunt, 1986). In addition, other researches such as Brotherton (1980) and Robertson (Robertson \& Makin, 1986) show that the recruitment process is too much based on subjective criteria, no matter how great variability between organizations exists.

The exact evaluation of job candidates is a complex process because of the difficulty of their skills and we may use fuzzy theory to handle uncertainty (Zadeh, 1968). It can improve the efficiency of assessments and reduce the subjective judgment. In the other words, most individuals prefer to declare their feelings with verbal expression. Fuzzy linguistic models allow the translation of verbal expressions into numerical ones.

Carlsson and Fuller (1996) apply fuzzy set theory in the decision making process under multi-criteria with incomplete or vague information. The primary objective of this work is that many real world problems have more to do with fuzziness than randomness as the major source of imprecision (Zimmerman, 1992). In such situations, it is more suitable to manage uncertainty by fuzzy set theory than by probability theory (Whalen, 1993).

In recent years, some research on the application of fuzzy set theory in HRM, mainly in the personnel recruitment, was undertaken (Cannavacciuolo et al., 1994; Liang \& Wang, 1992; Yaakob \& Kawata, 1999). Liang and Wang (1992) combined fuzzy set theory and weighted complete bipartite graphs to develop a polynomial time algorithm for solving employee recruitment. Chen and Cheng (2005) studied about selecting IS personnel implementation fuzzy GDSS based on metric distance methods. Lin (2009) introduced a job placement intervention using fuzzy approach for two-way choice. Zhang and Liu (2011) proposed a GRA-based intuitionistic fuzzy multi-criteria group decision making method for personnel selection.

This paper is organized as follows. The first section provides arithmetic operations of fuzzy numbers, and linguistic variable. In section two, fuzzy AHP is described. The formulation of fuzzy AHP are given is forwarded in section four. Briefly presents an illustrative example of the proposed approach and finally, limitations and future steps and research challenges are discussed in section five and six.

\section{Arithmetic operations of fuzzy numbers, and linguistic variable}

In this section, some important definitions will be reviewed.

Definition 1 (Fuzzy set). Let $\mathrm{X}$ be a universe of discourse, $\widetilde{M}$ is a fuzzy subset of $X$ if for all $x \in X$, there is a number $\mu_{\widetilde{M}}(x) \in[0,1]$ assigned to represent the membership of $x$ to $\widetilde{M}$, and $\mu_{\widetilde{M}}(x)$ is called the membership function of $\widetilde{M}$.

Definition 2 (Fuzzy number). A fuzzy number $\widetilde{M}$ is a normal and convex fuzzy subset of $X$. Here, the "Normality" implies that

$\exists x \in \mathbb{R} \quad \bigvee_{x} \mu_{\widetilde{M}}(x)=1$

and "Convex" means that

$\forall x_{1} \in X, \quad x_{2} \in X \quad \forall \alpha \in[0,1]$ 


$$
\mu_{\widetilde{M}}\left(\alpha x_{1}+(1-\alpha) x_{2}\right) \geq \min \left(\mu_{\widetilde{M}}\left(x_{1}\right), \mu_{\widetilde{M}}\left(x_{2}\right)\right) .
$$

Definition 3 (Arithmetic operations of fuzzy numbers). A triangular fuzzy number $\widetilde{M}$ (Kaufmann \& Gupta, 1991) can be defined by a triplet (a, b, c) shown in Fig. 1 The membership function is defined as

$$
\mu_{\widetilde{M}}(x)=\left\{\begin{array}{lr}
0, & x<a, \\
\frac{x-a}{b-a}, & a \leq x \leq b, \\
c-x \\
c-b & b \leq x \leq c, \\
0, & x>c,
\end{array}\right.
$$

The addition operations and multiplication operations of the triangular fuzzy numbers are articulated below:

Fuzzy number addition $\oplus$

$\left(a_{1}, b_{1}, c_{1}\right) \oplus\left(a_{2}, b_{2}, c_{2}\right)=\left(a_{1}+a_{2}, b_{1}+b_{2}, c_{1}+c_{2}\right)$

Fuzzy number multiplication $\otimes$

$$
\left(a_{1}, b_{1}, c_{1}\right) \otimes\left(a_{2}, b_{2}, c_{2}\right)=\left(a_{1} \times a_{2}, b_{1} \times b_{2}, c_{1} \times c_{2}\right)
$$

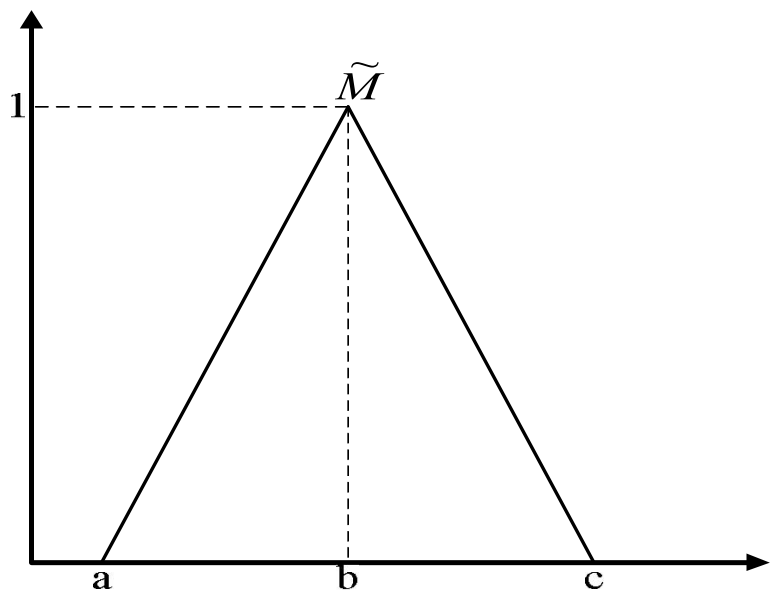

Fig. 1. A triangle fuzzy numbers $\widetilde{A}$

Definition 4 (Linguistic variable). A variable whose states are fuzzy numbers assigned to relevant linguistic terms.

Definition 5 A linguistic variable (Zimmermann, 1991) is characterized by a quintuple $(x, T(x), U, G, \widetilde{M})$.

1. $x$ is the name of the value.

2. $U$ is the universe of discourse, which is associated with the base variable $u$.

3. $T(x)$ denotes the term set of $x$, that is, the set of the name of linguistic value of $x$, with each value being a fuzzy variable denoted generically by $x$ and ranging over $U$.

4. $G$ is a syntactic rule for generating the name $X$, of values of $x$. A particular $X$, that is name generated by $G$, is called a term. 
5. $M$ is a semantic rule for associating with each $X$ its meaning, $\widetilde{M}(x)$ which is a fuzzy subset $U$.

\section{Fuzzy AHP}

FAHP method is a mathematical approach for alternative selection and justification problem by using the concepts of fuzzy set theory and hierarchical structure analysis. The decision maker can specify preferences in the form of natural language or numerical value about the importance of each performance attribute. The system combines these preferences using FAHP with existing data. In the FAHP method, the pair-wise comparisons in the judgment matrix are fuzzy numbers and use fuzzy arithmetic and fuzzy aggregation operators; the procedure calculates a sequence of weight vectors that will be used to choose main attribute.

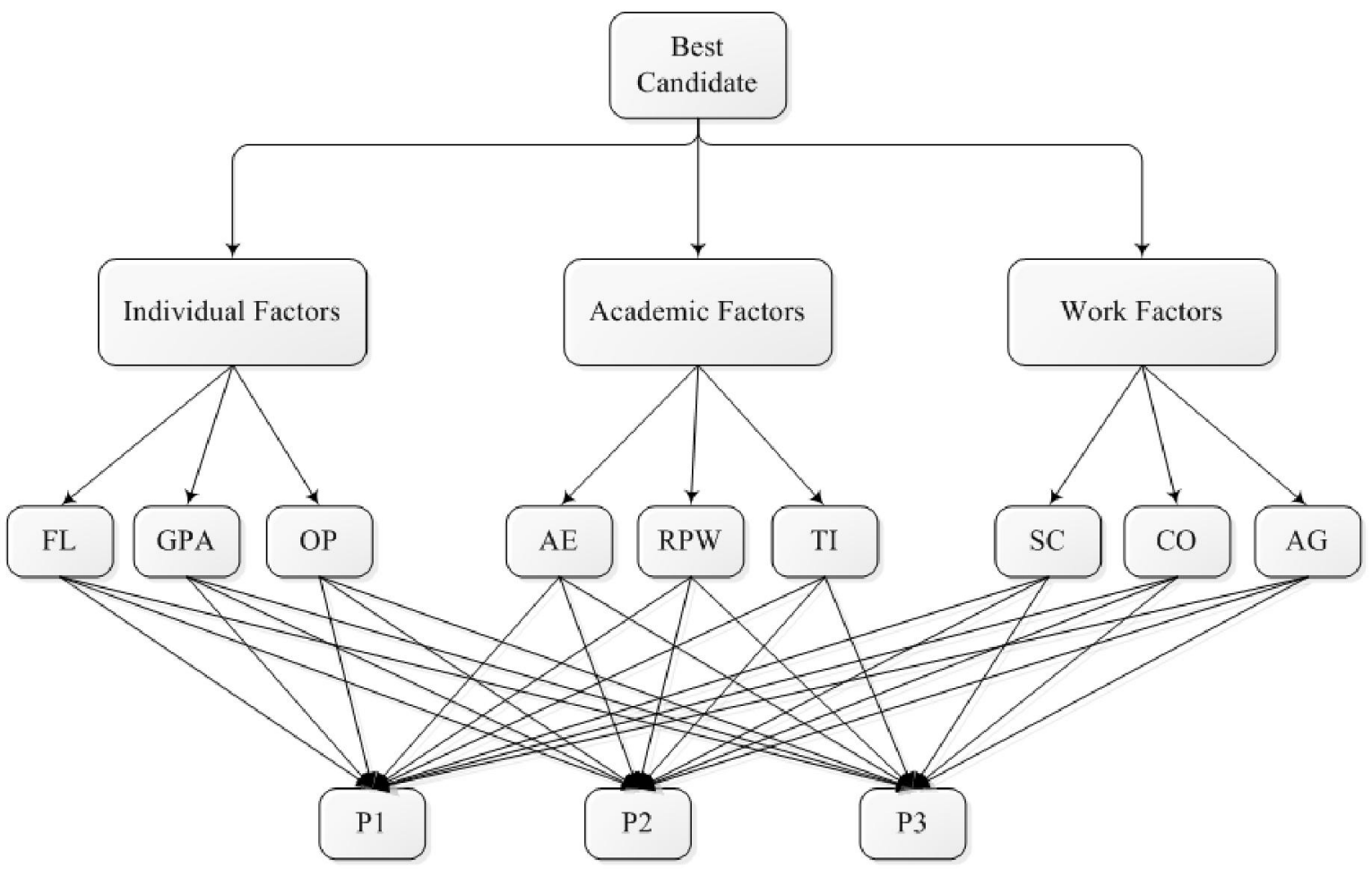

Fig. 2. The hierarchy of the problem

In the following, first, the outlines of the analysis method on FAHP are given and then the method is applied to a personnel selection problem. For easy computing, we summarize the algorithm for evaluating personnel selection problem by FAHP.

Step 1: The first step of FAHP consists of developing a hierarchical structure of the assessment problem. After developing the performance hierarchy, decision makers have to determine the relative weights of each criterion. In the AHP, weights are determined using pair-wise comparison between each pair of criteria. To determine relative weights, decision makers are asked to make pair-wise comparison using a 1-9 preference scale (Saaty, 1980). The pair-wise comparison data is organized in the form of fuzzy triangle numbers using Definition 3.

Step 2: If decision makers cannot utilize the preferences by the form of fuzzy triangle numbers, they can give preferences by linguistic terms, and use look-up tables for values, they can easily derive corresponding value of fuzzy numbers

(Definition 5 and Fig. 3) 


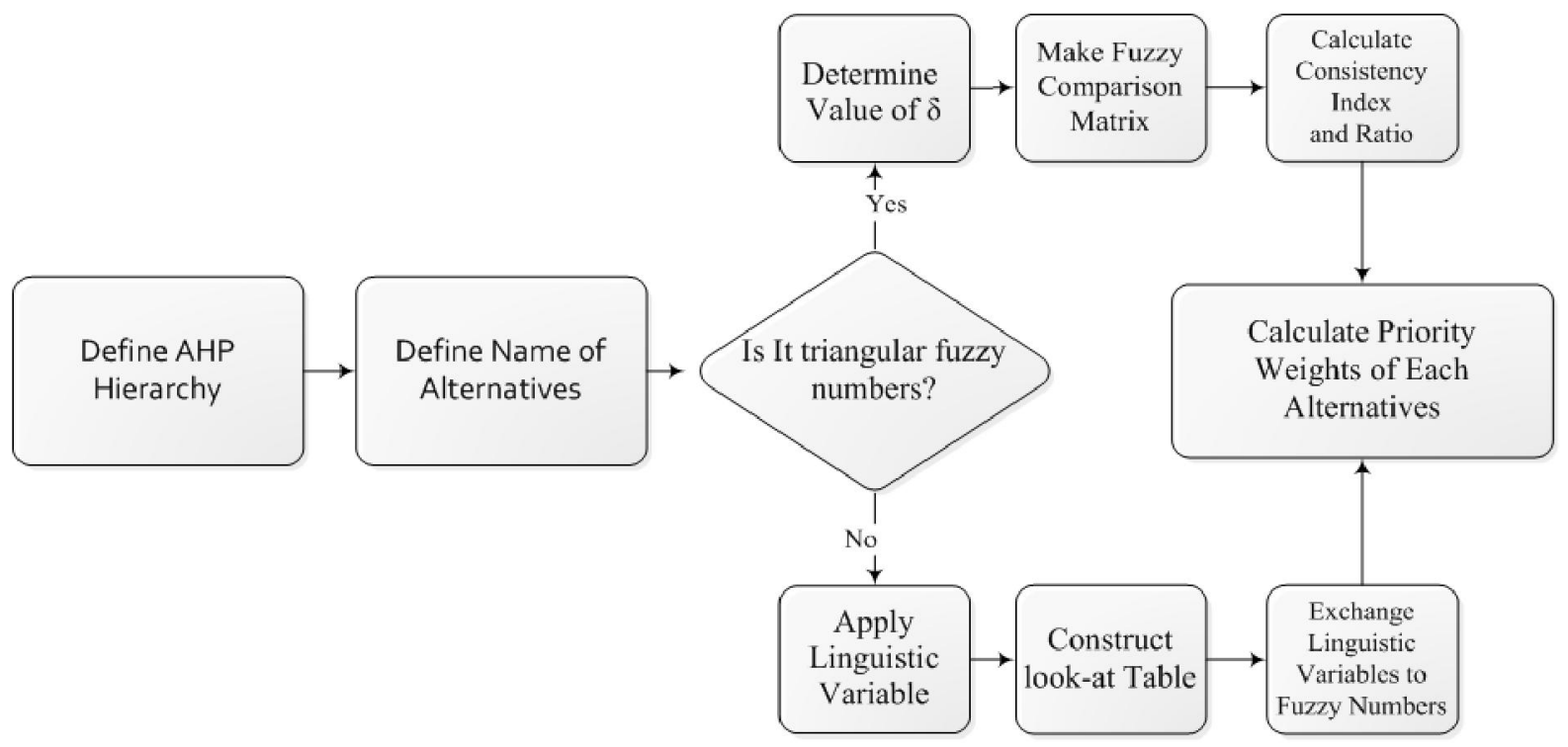

Fig. 3. Steps of fuzzy AHP

Step 3: After setting up the hierarchy and pair-wise comparisons of criteria of alternatives, it is necessary to calculate global value of priority of alternatives.

\section{Calculation steps of FAHP}

In the following, first the outlines of the extent analysis method on fuzzy AHP are given and then the method is applied for a catering firm selection problem. Let $X=\left\{x_{1}, x_{2}, \ldots, x_{\mathrm{n}}\right\}$ be an object set, and $U=\left\{u_{1}, u_{2}, \ldots, u_{\mathrm{n}}\right\}$ be a goal set. According to Chang (1996) in extent analysis, each object is taken and extent analysis for each goal, $g_{i}$, is performed, respectively. Therefore, $m$ extent analysis values for each object can be obtained, with the following signs:

$M_{g_{i}}^{1}, M_{g_{i}}^{2}, \ldots, M_{g_{i}}^{m} \quad i=1,2, \ldots, n$,

The steps of analysis can be given as in the following:

Step 1: The value of fuzzy synthetic extent with respect to the $i$ th object is defined as

$S_{i}=\sum_{j=1}^{m} M_{g_{i}}^{j} \otimes\left[\sum_{i=1}^{n} \sum_{j=1}^{m} M_{g_{i}}^{j}\right]^{-1}$

To obtain $\sum_{j=1}^{m} M_{g_{i}}^{j}$, perform the fuzzy addition operation of $m$ extent analysis values for a particular matrix such that

$\sum_{j=1}^{m} M_{g_{i}}^{j}=\left(\sum_{j=1}^{m} l_{j}, \sum_{j=1}^{m} m_{j}, \sum_{j=1}^{m} u_{j}\right)$

and to obtain $\left[\sum_{i=1}^{n} \sum_{j=1}^{m} M_{g_{i}}^{j}\right]^{-1}$, perform the fuzzy addition operation of $M_{g_{i}}^{j}(j=1,2, \ldots, m)$ values such that 
$\sum_{i=1}^{n} \sum_{j=1}^{m} M_{g_{i}}^{j}=\left(\sum_{j=1}^{n} l_{j}, \sum_{j=1}^{n} m_{j}, \sum_{j=1}^{n} u_{j}\right)$

and then we compute the inverse of the vector in Eq. (7) such that

$\left[\sum_{i=1}^{n} \sum_{j=1}^{m} M_{g_{i}}^{j}\right]^{-1}=\left(\frac{1}{\sum_{j=1}^{n} u_{j}}, \frac{1}{\sum_{j=1}^{n} m_{j}}, \frac{1}{\sum_{j=1}^{n} l_{j}}\right)$

Step 2: The degree of possibility of $M_{2}=\left(l_{2}, m_{2}, u_{2}\right) \geq M_{1}=\left(l_{1}, m_{1}, u_{1}\right)$ is defined as

$V\left(M_{2} \geq M_{1}\right)=\sup _{y \geq x}\left[\min \left(\mu_{M_{1}}(x), \mu_{M_{2}}(y)\right)\right]$

and Eq. (8) can be equivalently expressed as follows:

$V\left(M_{2} \geq M_{1}\right)=\left\{\begin{array}{lr}1 & \mathrm{~m}_{2} \geq \mathrm{m}_{1} \\ 0 & \mathrm{l}_{1} \geq \mathrm{u}_{2} \\ \frac{\mathrm{l}_{1}-\mathrm{u}_{2}}{\left(\mathrm{~m}_{2}-\mathrm{u}_{2}\right)-\left(\mathrm{m}_{1}-\mathrm{l}_{1}\right)} & \text { Otherwise }\end{array}\right\}$

Step 3: The degree possibility for a convex fuzzy number to be greater than $k$ convex fuzzy numbers $M_{i}(i=1,2, \ldots, k)$ can be defined by

$V\left(M \geq M_{1}, M_{2}, \ldots, M_{k}\right)=\min \left(V\left(M \geq M_{i}\right)\right) \quad \mathrm{i}=1,2, \ldots, \mathrm{k}$

Assume that

$d^{\prime}\left(A_{i}\right)=\min \left(V\left(S_{i} \geq S_{k}\right)\right) \mathrm{k}=1,2, \ldots, \mathrm{n} ; \mathrm{k} \neq \mathrm{i}$

Then the weight vector is given by

$W^{\prime}=\left(d^{\prime}\left(A_{1}\right), d^{\prime}\left(A_{2}\right), \ldots, d^{\prime}\left(A_{n}\right)\right)^{T}$

Step 4: The normalized weight vectors are

$W^{\prime}=\left(\mathrm{d}\left(\mathrm{A}_{1}\right), \mathrm{d}\left(\mathrm{A}_{2}\right), \ldots, \mathrm{d}\left(\mathrm{A}_{\mathrm{n}}\right)\right)^{\mathrm{T}}$

where $W$ is a nonfuzzy number.

\section{Numerical example}

The purpose of the empirical application is to illustrate the use of the proposed method. The experiment was basically setup upon a real life decision. Suppose that a research and development institute wants to select person. We assume that after the preliminary selection phase, three candidates (P1, P2, P3) are qualified for the final evaluation. For this selection process are established the following criteria: 1- Individual Factor (Foreign language, Bachelor Degree, Oral Presentation) 2Academic Factor (Academic Experience, Research Paper Writing, Technical information) 3- Work Factor (Self-confidence, Compatibility, Age). The goal is to select the best person among the alternatives. The hierarchy is shown in Fig. 2.

The fuzzy number is represented in Table 1 and the fuzzy evaluation matrix relevant to the goal is given in Table 2. The decision-making group now compares the sub-attributes with respect to mainattributes. First, they compare the sub-attributes of work factor. Table 3 gives the fuzzy comparison data of the sub-attributes of work factor. The other matrices of pair wise comparisons and the weight 
vector of each matrix are given in Table 4 and Table 5 . The sub attributes of work factor, individual factor and academic factor are shown in Table 6-8. The combination of priority weights for sub attributes, attributes, and alternatives to determine priority weights for the best person are given in Table 9.

Table 1

Fuzzy Numbers

Fuzzy language

Absolute (A)

Very Strong(VS)

Fairly Strong(FS)

Weak(W)

Fuzzy numbers

Equal(E)

$(7 / 2,4,9 / 2)$

$(5 / 2,3,7 / 2)$

$(3 / 2,2,5 / 2)$

$(2 / 3,1,3 / 2)$

$(1,1,1)$

\section{Table 2}

Value of First Hierarchy

\begin{tabular}{lccc}
\hline & Work Factor & Individual Factor & Academic Factor \\
\hline Work Factor & $(1,1,1)$ & $(3 / 2,2,5 / 2)$ & $(2 / 5,1 / 2,2 / 3)$ \\
Individual Factor & $(2 / 5,1 / 2,2 / 3)$ & $(1,1,1)$ & $(5 / 2,3,7 / 2)$ \\
Academic Factor & $(3 / 2,2,5 / 2)$ & $(2 / 7,1 / 3,2 / 5)$ & $(1,1,1)$ \\
\hline
\end{tabular}

The weight vector from Table 2 is calculated as $\mathrm{W}_{\mathrm{G}}=(0,1,0)^{\mathrm{T}}$

Table 3

The Evaluation Matrix Relevant to the Work Factor

\begin{tabular}{llll}
\hline & $\mathrm{SC}$ & $\mathrm{CO}$ & $\mathrm{Ag}$ \\
\hline $\mathrm{SC}$ & $(1,1,1)$ & $(2 / 5,1 / 2,2 / 3)$ & $(2 / 7,1 / 3,2 / 5)$ \\
$\mathrm{CO}$ & $(3 / 2,2,5 / 2)$ & $(1,1,1)$ & $(3 / 2,2,5 / 2)$ \\
$\mathrm{Ag}$ & $(5 / 2,3,7 / 2)$ & $(2 / 5,1 / 2,2 / 3)$ & $(1,1,1)$ \\
\hline
\end{tabular}

The weight vector from Table 3 is calculated as $\mathrm{W}_{\mathrm{WF}}=(0,0.54,0.46)^{\mathrm{T}}$

Table 4

The Evaluation Matrix Relevant to the Academic Factor

\begin{tabular}{llll}
\hline & AE & RPW & TI \\
\hline AE & $(1,1,1)$ & $(2 / 5,1 / 2,2 / 3)$ & $(2 / 5,1 / 2,2 / 3)$ \\
RPW & $(3 / 2,2,5 / 2)$ & $(1,1,1)$ & $(2 / 3,1,3 / 2)$ \\
TI & $(3 / 2,2,5 / 2)$ & $(2 / 3,1,3 / 2)$ & $(1,1,1)$ \\
\hline
\end{tabular}

The weight vector from Table 4 is calculated as $\mathrm{W}_{\mathrm{AF}}=(0.06,0.47,0.47)^{\mathrm{T}}$

Table 5

The Evaluation Matrix Relevant to the Individual Factor

\begin{tabular}{llll}
\hline & FL & GPA & OP \\
\hline FL & $(1,1,1)$ & $(2 / 5,1 / 2,2 / 3)$ & $(2 / 5,1 / 2,2 / 3)$ \\
GPA & $(3 / 2,2,5 / 2)$ & $(1,1,1)$ & $(2 / 3,1,3 / 2)$ \\
OP & $(3 / 2,2,5 / 2)$ & $(2 / 3,1,3 / 2)$ & $(1,1,1)$ \\
\hline
\end{tabular}

The weight vector from Table 5 is calculated as $\mathrm{W}_{\mathrm{IF}}=(0.06,0.47,0.47)^{\mathrm{T}}$ 
Table 6

Linguistic Evaluations of Alternatives According to $\mathrm{SC} / \mathrm{CO} / \mathrm{AG}$

\begin{tabular}{lccc}
\hline & $\mathrm{P} 1$ & $\mathrm{P} 2$ & $\mathrm{P} 3$ \\
\hline P1 & $(1,1,1) /(1,1,1) /(1,1,1)$ & $(5 / 2,3,7 / 2) /(2 / 3,1,3 / 2) /(2 / 3,1,3 / 2)$ & $(3 / 2,2,5 / 2) /(2 / 9,1 / 4,2 / 7) /(2 / 7,1 / 3,2 / 5)$ \\
P2 & $(2 / 7,1 / 3,2 / 5) /(2 / 3,1,3 / 2) /(2 / 3,1,3 / 2)$ & $(1,1,1) /(1,1,1) /(1,1,1)$ & $(2 / 7,1 / 3,2 / 5) /(2 / 5,1 / 2,2 / 3) /(2 / 5,1 / 2,2 / 3)$ \\
P3 & $(2 / 5,1 / 2,2 / 3) /(7 / 2,4,9 / 2) /(5 / 2,3,7 / 2)$ & $(5 / 2,3,7 / 2) /(3 / 2,2,5 / 2) /(3 / 2,2,5 / 2)$ & $(1,1,1) /(1,1,1) /(1,1,1)$ \\
\hline
\end{tabular}

The weight vector from Table 6 is calculated as $\mathrm{W}_{\mathrm{SC}}=(0.66,0,0.34)^{\mathrm{T}}, \mathrm{W}_{\mathrm{CO}}=(0,0,1)^{\mathrm{T}}, \mathrm{W}_{\mathrm{AG}}=(0,0,1)^{\mathrm{T}}$.

Table 7

Linguistic Evaluations of Alternatives According to AE/RPW/TI

\begin{tabular}{llll}
\hline & $\mathrm{P} 1$ & $\mathrm{P} 2$ & $\mathrm{P} 3$ \\
\hline $\mathrm{P} 1$ & $(1,1,1) /(1,1,1) /(1,1,1)$ & $(2 / 7,1 / 3,2 / 5) /(5 / 2,3,7 / 2) /(2 / 9,1 / 4,2 / 7)$ & $(2 / 3,1,3 / 2) /(2 / 3,1,3 / 2) /(2 / 7,1 / 3,2 / 5)$ \\
$\mathrm{P} 2$ & $(5 / 2,3,7 / 2) /(2 / 7,1 / 3,2 / 5) /(7 / 2,4,9 / 2)$ & $(1,1,1) /(1,1,1) /(1,1,1)$ & $(1,1,1) /(1,1,1) /(2 / 7,1 / 3,2 / 5)$ \\
$\mathrm{P} 3$ & $(2 / 3,1,3 / 2) /(2 / 3,1,3 / 2) /(5 / 2,3,7 / 2)$ & $(1,1,1) /(1,1,1) /(5 / 2,3,7 / 2)$ & $(1,1,1) /(1,1,1) /(1,1,1)$ \\
\hline
\end{tabular}

The weight vector from Table 7 is calculated as $\mathrm{W}_{\mathrm{AE}}=(0,0,1)^{\mathrm{T}}, \mathrm{W}_{\mathrm{RPW}}=(0.87,0,0.13)^{\mathrm{T}}, \mathrm{W}_{\mathrm{TI}}=(0$, $0.31,0.69)^{\mathrm{T}}$

Table 8

Linguistic Evaluations of Alternatives According to FL/GPA/OP

\begin{tabular}{llll}
\hline & $\mathrm{P} 1$ & $\mathrm{P} 2$ & $\mathrm{P} 3$ \\
\hline P1 & $(1,1,1) /(1,1,1) /(1,1,1)$ & $(2 / 3,1,3 / 2) /(7 / 2,4,9 / 2) /(3 / 2,2,5 / 2)$ & $(1,1,1) /(5 / 2,3,7 / 2) /(2 / 7,1 / 3,2 / 5)$ \\
P2 & $(2 / 3,1,3 / 2) /(2 / 9,1 / 4,2 / 7) /(2 / 5,1 / 2,2 / 3)$ & $(1,1,1) /(1,1,1) /(1,1,1)$ & $(2 / 9,1 / 4,2 / 7) /(1,1,1) /(7 / 2,4,9 / 2)$ \\
P3 & $(1,1,1) /(2 / 7,1 / 3,2 / 5) /(5 / 2,3,7 / 2)$ & $(7 / 2,4,9 / 2) /(1,1,1) /(2 / 9,1 / 4,2 / 7)$ & $(1,1,1) /(1,1,1) /(1,1,1)$ \\
\hline
\end{tabular}

The weight vector from

Table 8 is calculated as $\mathrm{W}_{\mathrm{FL}}=(0.27,0.18,0.55)^{\mathrm{T}}, \mathrm{W}_{\mathrm{GPA}}=(1,0,0)^{\mathrm{T}}, \mathrm{W}_{\mathrm{OP}}=(0.05,0.64,0.31)^{\mathrm{T}}$

\section{Conclusions}

Selecting the right employees in any organization is a key element in a today's competitive world and the information technology can contribute to this goal. In this paper, we have presented an algorithm for employee selection by considering fuzzy logic to handle uncertainty. The use of fuzzy logic has become one of the current trends in the treatment of the problem of the personnel selection because it allows us to represent the uncertainty, which exist in the process. As a future study, we may attempt to compare the results of this approach with other methods such as PROMETHEE, VIKTOR, ELECTRE, DRSA, PAPRIKA, IMRA, and ANP.

Table 9

Summary combination of priority weights

\begin{tabular}{lllll}
\hline \multicolumn{4}{l}{ Sub-attributes of Work Factor } & \\
& SC & CO & AG & Alternative Priority Weight \\
\hline Weight & 0 & 0.54 & 0.46 & \\
\hline
\end{tabular}

Alternative

\begin{tabular}{lllll}
\hline P1 & 0.66 & 0 & 0 & 0 \\
P2 & 0 & 0 & 0 & 0 \\
P3 & 0.34 & 1 & 1 & 1 \\
\hline
\end{tabular}

Sub-attributes of Academic Factor

\begin{tabular}{lllll}
\hline & AE & RPW & TI & Alternative Priority Weight \\
\hline Weight & 0.06 & 0.47 & 0.47 & \\
\hline
\end{tabular}




\begin{tabular}{lllll}
\hline Alternative & \multicolumn{3}{l}{} \\
\hline P1 & 0 & 0.87 & 0 & 0.47 \\
P2 & 0 & 0 & 0.31 & 0.14 \\
P3 & 1 & 0.13 & 0.69 & 0.39 \\
\hline
\end{tabular}

Sub-attributes of Individual Factor

\begin{tabular}{lllll}
\hline & FL & GPA & OP & Alternative Priority Weight \\
\hline Weight & 0.06 & 0.47 & 0.47 & \\
\hline
\end{tabular}

\begin{tabular}{lllll} 
Alternative & \multicolumn{5}{l}{} \\
\hline P1 & 0.27 & 1 & 0.05 & 0.56 \\
P2 & 0.18 & 0 & 0.64 & 0.30 \\
P3 & 0.55 & 0 & 0.31 & 0.14 \\
\hline
\end{tabular}

Main attributes of the goal

\begin{tabular}{lllll}
\hline & Work & Individual & Academic & Alternative Priority Weight \\
& Factor & Factor & Factor & \\
\hline Weight & 0 & 1 & 0 & \\
\hline
\end{tabular}

\section{Alternative}

\begin{tabular}{|c|c|c|c|c|}
\hline P1 & 0 & 0.47 & 0.56 & 0.51 \\
\hline P2 & 0 & 0.14 & 0.30 & 0.21 \\
\hline P3 & 1 & 0.39 & 0.14 & 0.28 \\
\hline
\end{tabular}

\section{References}

Blum, M. L., \& Naylor, J. C. (1968). Industrial psychology: Its theoretical and social foundations. New York: Harper \& Row.

Blunt, P. (1986). Human resource management. Melbourne: Longman Cheshire.

Bowen, D., Gilliland, S., \& Folger, R. (1999). HRM and service fairness: How being fair with employees spills over to customers. Organizational Dynamics .

Brotherton, C. (1980). Paradigm of selection validation: Some comments in the light of British equal opportunities legislation. 73-79.

Cannavacciuolo, A., Capaldo, G., Ventre, A., \& Zollo, G. (1994). Linking the fuzzy set theory to organizational routines: a study in personnel evaluation in a large company. 515-520.

Carlsson, C., \& Fuller, R. (1996). Fuzzy multiple criteria decision making: Recent developments. 78, 139-153.

Chang, D.-Y. (1996). Applications ofthe extent analysis method on fuzzy AHP. European Journal of Operational Research, 95, 649-655.

Chen, L., \& Cheng, C. (2005). Selecting IS personnel use fuzzy GDSS based on metric distance methods. $160,803-820$.

Freyd, M. (1923). Measurement in personnel selection: An outline of research procedure. 2, 215-249.

Kaufmann, A., \& Gupta, M. (1991). Introduction to Fuzzy. New York: Van Nostrand.

Liang, G. S., \& Wang, M. J. (1992). Personnel placement in a fuzzy environment. 19, 107-121.

Lin, H. (2009). A job placement intervention using fuzzy approach for two-way choice. 36, 25432553.

Robertson, I. T., \& Makin, P. J. (1986). Management selection in Britain: A survey and critique. 59, 45-57.

Saaty, T. (1980). The Analytic Hierarchy Process. Mc Graw-Hill. 
Whalen, T. (1993). Decision making under uncertainty with various assumptions about available information. 757-776.

Yaakob, S. B., \& Kawata, S. (1999). Workers' placement in an industrial environment. 106, 289-297. Zadeh, L. A. (1968). Fuzzy sets. 8, 338-353.

Zadeh, L. A. (1975). The concept of a linguistic variable and its application to approximate reasoning. Part 1:8:199-249, Part 2:8:301-357, Part 3:9:43 80,.

Zhang, S., \& Liu, S. (2011). A GRA-based intuitionistic fuzzy multi-criteria group decision making method for personnel selection. 38, 11401-11405.

Zimmerman, H. J. (1992). Fuzzy set theory and its application. Boston: Kluwer Academic Publishers.

Zimmermann, H. (1991). Fuzzy Set Theory and its Applications. Boston: Kluwer Academic Publishers. 